\title{
Differential gene expression profiles in spontaneously hypertensive rats induced by administration of enalapril and nifedipine
}

\author{
KI-MO LEE ${ }^{1}$, HAENG-A KANG ${ }^{1}$, CHANG-BO KO $^{1}$, EUN-HA OH $^{1}$, MIN PARK $^{1}$, HWA-YOUN LEE ${ }^{1}$, \\ HA-RIM CHOI ${ }^{2}$, CHUL-HO YUN ${ }^{1}$, WOON-WON JUNG ${ }^{3}$, JAE-WOOK OH ${ }^{4}$ and HYUNG-SIK KANG ${ }^{1}$ \\ ${ }^{1}$ School of Biological Sciences and Technology, Chonnam National University, Gwangju 500-757; ${ }^{2}$ Department of \\ Food and Nutrition, Nambu University, Gwangju 506-706; ${ }^{3}$ College of Health Sciences, Korea University, \\ Seoul 136-70; ${ }^{4}$ Division of Animal Life Science, College of Animal Bioscience and \\ Technology, Konkuk University, Seoul 143-701, Republic of Korea
}

Received August 14, 2012; Accepted October 18, 2012

DOI: 10.3892/ijmm.2012.1183

\begin{abstract}
Enalapril and nifedipine are used as antihypertensive drugs; however, the therapeutic target molecules regulated by enalapril and nifedipine have yet to be fully identified. The aim of this study was to identify novel target genes that are specifically regulated by enalapril and nifedipine in tissues from spontaneously hypertensive rats (SHR) using DNA microarray analysis. We found that administration of SHR with enalapril and nifedipine differentially regulated 33 genes involved in the pathogenesis of cardiovascular diseases. Furthermore, we identified 16 genes that have not previously been implicated in cardiovascular diseases, including interleukin-24 (IL-24). Among them, exogenous administration of IL-24 attenuated the expression of vascular inflammation and hypertension-related genes induced by $\mathrm{H}_{2} \mathrm{O}_{2}$ treatment in mouse vascular smooth muscle (MOVAS) cells. This study provides valuable information for the development of novel antihypertensive drugs. In addition, the genes identified may be of use as biomarkers and therapeutic targets for cardiovascular diseases, including hypertension.
\end{abstract}

\section{Introduction}

Hypertension plays a causative role in the onset of stroke, myocardial infarction, heart failure, peripheral arterial disease, and chronic kidney disease. Hypertension can be classified as either essential or secondary. Due to a similar pathophysiology, spontaneously hypertensive rats (SHR) are widely used as an animal model for essential hypertension in humans (1). The SHR strain was derived from outbred Wistar-Kyoto (WKY) rats by selective breeding of animals that had high blood pres-

Correspondence to: Professor Hyung-Sik Kang, School of Biological Sciences and Technology, Chonnam National University, 77 Yongbong-ro, Buk-gu, Gwangju 500-757, Republic of Korea E-mail:kanghs@jnu.ac.kr

Key words: spontaneously hypertensive rat, enalapril, nifedipine, interleukin-24, vascular smooth muscle cells sure. Thus, the normotensive WKY rats were used as controls for SHR (2).

Currently, antihypertensive drugs include thiazide diuretics, angiotensin converting enzyme (ACE) inhibitors, calcium channel blockers, $\beta$-blockers, and angiotensin II receptor antagonists (3). Enalapril is an ACE inhibitor that lowers blood pressure by reducing plasma levels of angiotensin II (4). Enalapril has also been shown to reduce progression of carotid intimal and medial thickening, constriction of blood vessels and aldosterone secretion in patients with hypertension and/or diabetes (5). Nifedipine is an L-type calcium channel blocker of the dihydropyridine family, which inhibits the transmembrane influx of calcium ions into cardiac and vascular smooth muscle cells (6). Nifedipine causes arterial vasodilation, reduced muscle contraction, inhibition of reactive oxygen species (ROS) production, and vascular smooth muscle cell proliferation (7). However, the therapeutic target molecules regulated by the action of enalapril and nifedipine remain to be fully identified.

To identify the genes involved in the pathogenesis of cardiovascular diseases, including hypertension, we used DNA microarray analysis to establish gene expression profiles in heart, brain, and liver tissues from SHR, compared with the WKY controls, as well as after administration of antihypertensive drugs. The aim of this study was to: i) identify target genes that are specifically regulated by enalapril and nifedipine in an established animal model of essential hypertension, and ii) provide novel insight into therapeutic antihypertension strategies using enalapril and nifedipine.

\section{Materials and methods}

Administration of antihypertensive drugs in WKY and SHR. Enalapril and nifedipine were obtained from Sigma-Aldrich (St. Louis, MO, USA). Specific pathogen free 8-9-week-old male SHR and WKY rats were obtained from the Samtaco Animal Breeding Company (Osan, South Korea). All in vivo studies were approved by the Institutional Animal Care and Use Committee, Chonnam National University. Enalapril (40 mg/kg/day) or nifedipine (30 mg/kg/day) were administered orally every day for 3 weeks. The dosage and duration 
of administration were calculated considering the maximum therapeutic dose in humans and based on previous studies $(8,9)$.

Measurement of systolic blood pressure. Systolic blood pressure (SBP) was measured using the CODA system (Kent Scientific Corporation, Torrington, CT, USA) as previously described (10). SBP and body weight were evaluated every week. After 3 weeks of administration, the rats were sacrificed and tissue weights of the heart, brain and liver were determined.

RNA extraction. Samples of heart, brain and liver were homogenized, and total RNA was extracted using TRIzol ${ }^{\circledR}$ reagent (Molecular Research Center, Inc., Cincinnati, OH, USA). The concentration and purity of the total RNA were determined spectrophotometrically at 260 and $280 \mathrm{~nm}$ using an Agilent ${ }^{\mathrm{TM}}$ Bioanalyzer (Agilent Technologies, Palo Alto, CA, USA).

DNA microarray analysis. Differential gene expression was measured using CodeLink Rat Whole Genome Bioarrays ( $<34,000$ genes; Amersham, Piscataway, NJ, USA) following the manufacturer's protocol, and the data were analyzed as previously described (11). Briefly, for first-strand cDNA synthesis, $5 \mu \mathrm{g}$ of total RNA was heated at $70^{\circ} \mathrm{C}$ for $10 \mathrm{~min}$ with control bacterial mRNA and a T7 oligo(dT) primer, followed by incubation with first-strand reaction components (10X buffer, $5 \mathrm{mM}$ dNTP, RNase inhibitor and reverse transcriptase) for $1 \mathrm{~h}$ at $42^{\circ} \mathrm{C}$. The second strand was produced by incubation of first-strand cDNA products with second-strand reaction components (10X buffer, $5 \mathrm{mM}$ dNTP, RNase $\mathrm{H}$, DNA polymerase) for $2 \mathrm{~h}$ at $16^{\circ} \mathrm{C}$. Double-stranded cDNA was purified using a QIAquick purification kit (Qiagen, Valencia, CA, USA). Purified double-stranded cDNA was incubated at $37^{\circ} \mathrm{C}$ for $14 \mathrm{~h}$ with IVT mix (10X reaction buffer, biotinylated UTP, UTP, ATP, CTP, GTP and T7 enzyme) to enable in vitro transcription of cRNA. The biotin-labeled cRNA was purified using the Qiagen RNeasy mini kit (Qiagen). A mixture of $10 \mu \mathrm{g}$ of cRNA and $5 \mathrm{X}$ fragmentation buffer was incubated at $94^{\circ} \mathrm{C}$ for $20 \mathrm{~min}$, and then hybridized at $90^{\circ} \mathrm{C}$ for $5 \mathrm{~min}$. After chilling on ice for $10 \mathrm{~min}$, the hybridization mixtures were slowly injected into sealed microarray slides. The slides were shaken at $37^{\circ} \mathrm{C}$ and $300 \mathrm{rpm}$ for $18-24 \mathrm{~h}$ prior to incubation at $46^{\circ} \mathrm{C}$ for $1 \mathrm{~h}$ with preheated $0.75 \mathrm{X}$ TNT buffer [1X TNT: $0.1 \mathrm{M}$ Tris- $\mathrm{HCl}$ (pH 7.6), $0.15 \mathrm{M} \mathrm{NaCl}$, and $0.05 \%$ Tween-20], followed by incubation at room temperature for $30 \mathrm{~min}$ with $3.4 \mathrm{ml}$ of Cy5-streptavidin working solution. The slides were washed four times with 1X TNT buffer for $5 \mathrm{~min}$ and then rinsed with $0.1 \mathrm{X} \mathrm{SSC} / 0.05 \% \mathrm{Tween}^{\mathrm{TM}}$ for $30 \mathrm{sec}$. Hybridization to the arrays was detected using a ScanArray Express scanner (Packard BioScience, Meriden, CT, USA) with the laser set at $635 \mathrm{~nm}$. After scanning, the array images were analyzed by ImaGene 6.0 and GeneSight 4.1 software.

Treatment of MOVAScells with interleukin-24(IL-24). MOVAS cells $\left(1 \times 10^{5} / \mathrm{ml}\right)$, an immortalized mouse vascular aorta smooth muscle cells, were grown in DMEM supplemented with $10 \%$ FBS and $1 \%$ penicillin-streptomycin (Gibco-BRL, Rockville, NY, USA) at $37^{\circ} \mathrm{C}$ in a humidified atmosphere containing $5 \% \mathrm{CO}_{2}$. When the cells were $70 \%$ confluent, the medium was replaced with serum-free DMEM. After serum starvation for $12 \mathrm{~h}$, the cells were treated with $0.3 \mathrm{mM} \mathrm{H}_{2} \mathrm{O}_{2}$
(Merck, Darmstadt, Germany) for $6 \mathrm{~h}$ in the presence or absence of recombinant human (rh) IL-24 (50 ng/ml; R\&D Systems, Inc., Minneapolis, MN, USA).

RT-PCR and real-time PCR. Total RNA was isolated using TRIzol ${ }^{\circledR}$ reagent (Molecular Research Center, Inc.). Firststrand cDNA was synthesized from $5.0 \mu \mathrm{g}$ of total RNA using an M-MLV reverse transcriptase kit (Promega, Madison, WI, USA), according to the manufacturer's instructions. For RT-PCR, the synthesized cDNAs were added to a PCR mixture consisting of 10XPCR buffer, $0.25 \mathrm{mM}$ dNTP, 0.5 unit TaqDNA polymerase and 10 pmol of gene-specific primers. Primers used for PCR were: angiotensinogen, 5'-gtacagacagcaccctactt-3' and 5'-cacgtcacggagaagttgtt-3'; endothelin-1, 5'-agctggtggaaggaaggaaactacg-3' and 5'-gacagtgcagaaaggtgaggtagac-3'; angiotensin II type 1 receptor-associated protein (ATRAP), 5'-tgcttggggcaacttcactatc-3' and 5'-acggtgcatgtggtagacgag-3'; platelet-derived growth factor (PDGF), 5'-tccagcgacaaggaacagaacg-3' and 5'-ggagattcagattcaccactttgc-3'; $\beta$-actin, 5'-gagatggccactgccgcatcctct-3' and 5'-atggtgctaggagccagagcagta-3'. PCR amplification was performed using 26 cycles ( $\beta$-actin) or 28 cycles (all others) at $95^{\circ} \mathrm{C}$ for $1 \mathrm{~min}, 56^{\circ} \mathrm{C}$ for $1 \mathrm{~min}$, and $72^{\circ} \mathrm{C}$ for $2 \mathrm{~min}$, followed by a final extension for $10 \mathrm{~min}$ at $72^{\circ} \mathrm{C}$. Equal volumes of reaction mixture from each sample were loaded onto $1 \%$ agarose gels and visualized by ethidium bromide staining.

Real-time PCR amplifications were performed in 48-well plates in a MiniOpticon ${ }^{\mathrm{TM}}$ Real-Time PCR Detection System (Bio-Rad Laboratories, Inc., USA) in a total volume of $10 \mu \mathrm{l}$, including $1 \mu \mathrm{l}$ of template cDNA, $10 \mathrm{pmol}$ of gene-specific primers and iQ SYBR-Green Supermix (Bio-Rad Laboratories, Inc.). Each sample was analyzed in triplicate. Primers used for PCR were: myocyte enhancer factor 2D (Mef2d), 5'-cagcagccagcactacagag-3' and 5'-ggcagggatgaccttgttta-3'; IL-24, 5'-ggcctgagcctaatccttct-3' and 5'-ctgcagaacctgtggtttca-3'; occludin, 5'-gagggtacacagacccaga-3' and 5'-caggattgcgctgactatga-3'; peroxisome proliferator-activated receptor $\delta$ (Ppar $\delta$ ), 5'-aacatcccaacttcagcag-3' and 5'-tactgcgcaagaactcatgg-3'; triadin, 5'-gcttccagacctgctttgtc-3' and 5'-ggctcttttcctttcccatc-3'; moesin, 5'-cccaaagagtcttggagcag-3' and 5'-atgttgagacccaaggcatc-3'; guanosine monophosphate reductase (Gmpr), 5'-gatgtggccaatgggtattc-3' and 5'-ccgactcccacttgatgat-3'; $\beta$-actin, 5'-attgttaccaactgggacgacatg-3' and 5'-cttcatgaggtagtctgtcaggtc-3'. PCR amplification was performed as follows: $95^{\circ} \mathrm{C}$ for $15 \mathrm{~min}$, followed by 48 cycles at $95^{\circ} \mathrm{C}$ for $30 \mathrm{sec}, 55^{\circ} \mathrm{C}$ for $30 \mathrm{sec}$, and $72^{\circ} \mathrm{C}$ for $30 \mathrm{sec}$. All data were normalized to $\beta$-actin expression levels.

Statistical analysis. For statistical analysis of data, P-values were analyzed using a two-way ANOVA and post-hoc test. Results are expressed as the means \pm SEM, and differences are considered statistically significant when $\mathrm{P}<0.05$.

\section{Results}

SBP, body and tissue weights. SBP levels of SHR were higher than those of WKY rats $(128 \pm 11 \mathrm{mmHg}$ in WKY vs. $186 \pm 10 \mathrm{mmHg}$ in SHR, $\mathrm{P}<0.05)$, while administration with enalapril or nifedipine for 3 weeks significantly decreased SBP levels of SHR $(186 \pm 10 \mathrm{mmHg}$ in SHR vs. $144 \pm 9 \mathrm{mmHg}$ in 


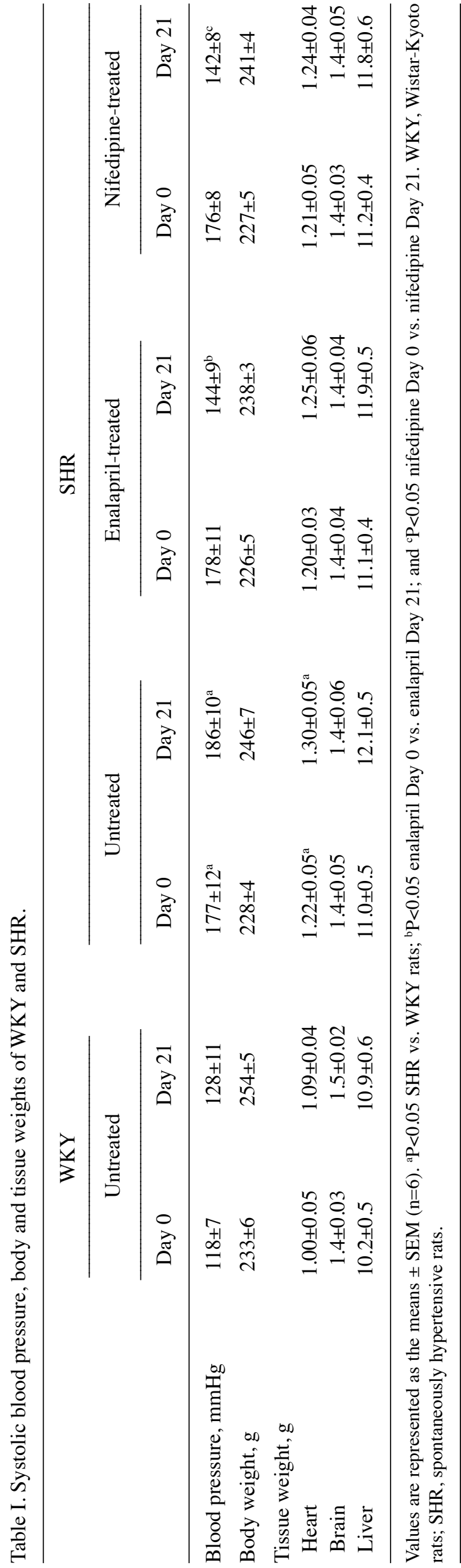

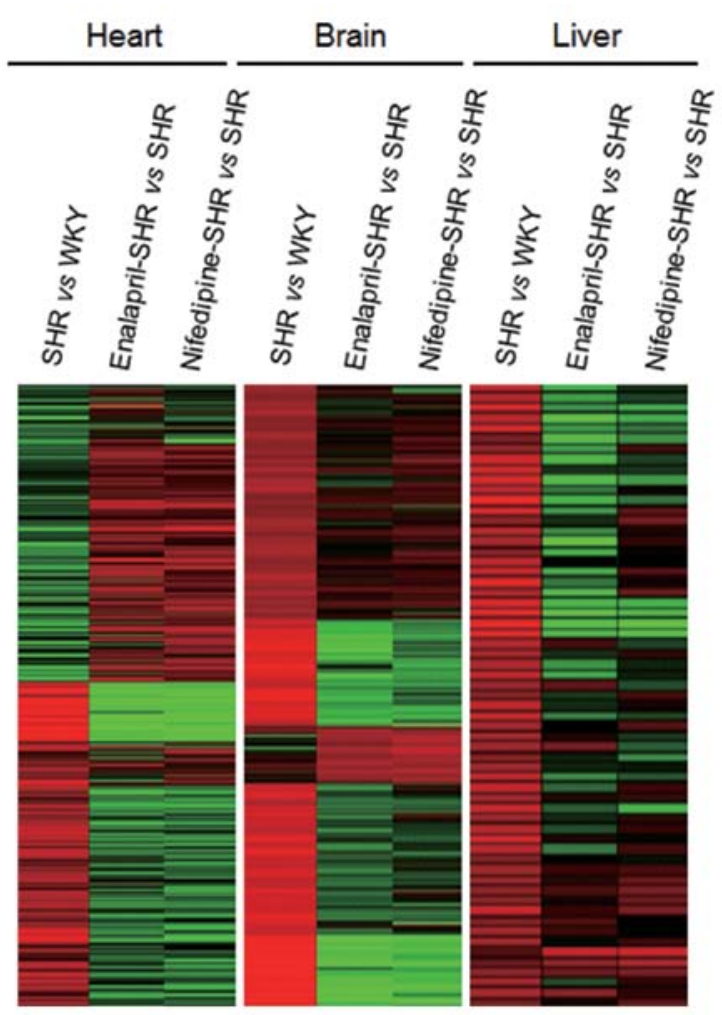

Figure 1. Cluster analysis of gene expression in different organs of WKY and SHR as well as SHR treated with antihypertensive drugs. Gene expression profiles were clustered using the K-means algorithm. Columns represent genes ordered according to their hierarchical distances. The red, green and black colors denote upregulated, downregulated and unchanged expression compared with the average expression levels, respectively.

enalapril-treated SHR, $\mathrm{P}<0.05$ or $142 \pm 8 \mathrm{mmHg}$ in nifedipinetreated SHR, P<0.05) (Table I). SHR had a lower body weight than WKY $(233 \pm 6 \mathrm{~g}$ in WKY vs. $228 \pm 6 \mathrm{~g}$ in SHR, Day 0; $254 \pm 5 \mathrm{~g}$ in WKY vs. $246 \pm 7 \mathrm{~g}$ in SHR, Day 21) (Table I). The heart weights of SHR were greater than those of the WKY rats $(1.00 \pm 0.05 \mathrm{~g}$ in WKY vs. $1.22 \pm 0.05 \mathrm{~g}$ in SHR, Day 0; $1.09 \pm 0.004 \mathrm{~g}$ in WKY vs. $1.30 \pm 0.05 \mathrm{~g}$ in SHR, Day $21, \mathrm{P}<0.05$ ), but weights of the brain and liver did not show apparent differences between SHR and WKY rats. Administration with enalapril or nifedipine did not significantly affect the body and tissue weights in SHR (Table I).

Effects of nifedipine and enalapril on differential gene expression in the heart, brain and liver from SHR. We used 34K gene chip microarray analysis to identify differentially expressed genes in the heart, brain, and liver from WKY and SHR as well as SHR treated with antihypertensive drugs. In total, 4,020 genes were found to be differentially expressed, with expression profiles clustering into three different groups using the K-means algorithm (Fig. 1). Heart, brain and liver samples showed 1,146, 265 and 172 upregulated genes, respectively, in SHR compared with the WKY controls. Administration of enalapril in SHR decreased the expression of 948, 104 and 45 of these same genes in the heart, brain and liver, respectively, compared with the untreated SHR. Similarly, nifedipine administration decreased the expression of 921,111 and 69 of these genes in the heart, brain and liver, respectively. 


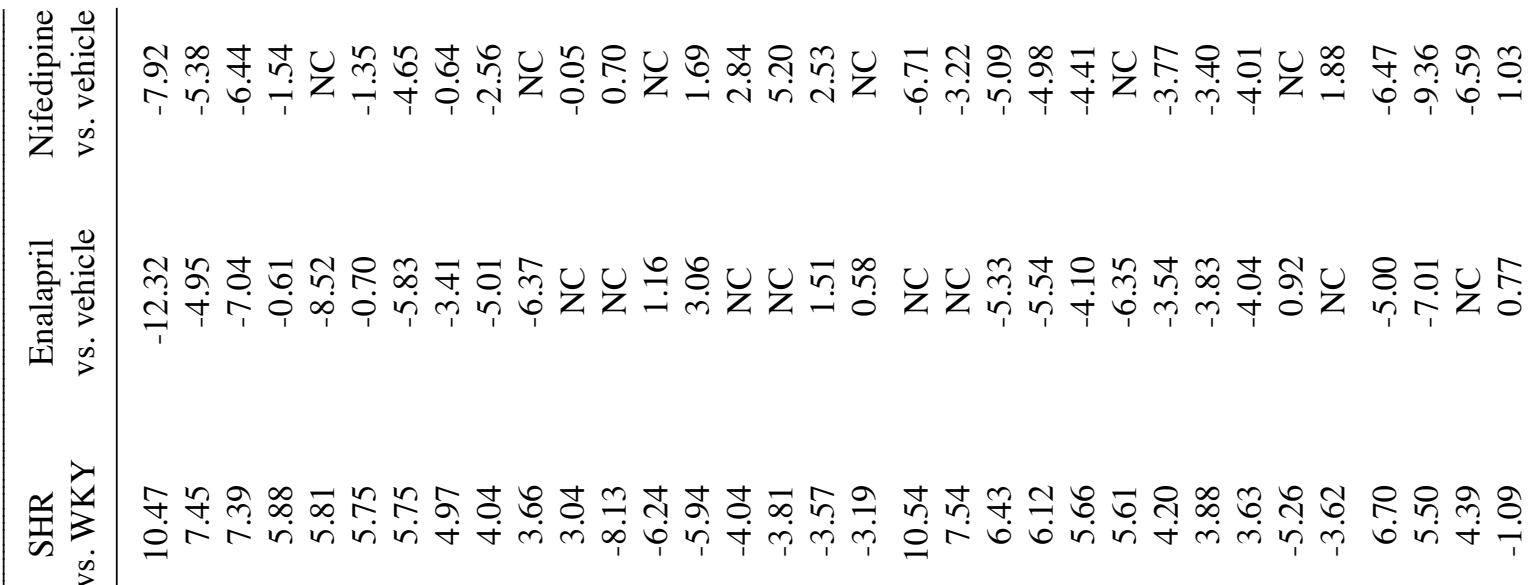

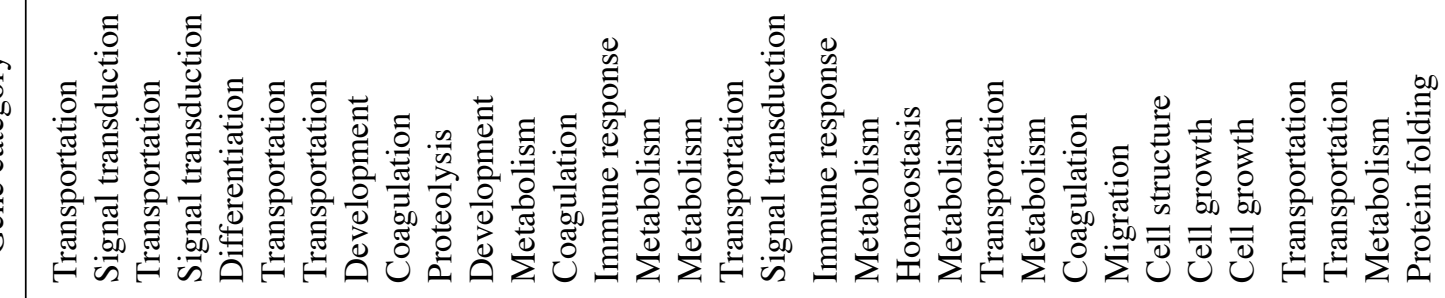

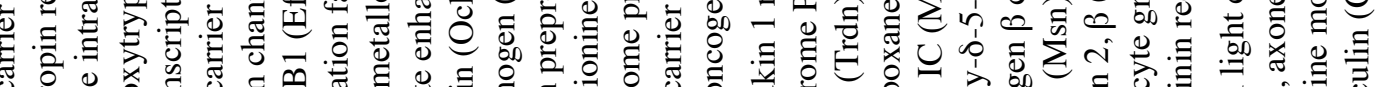

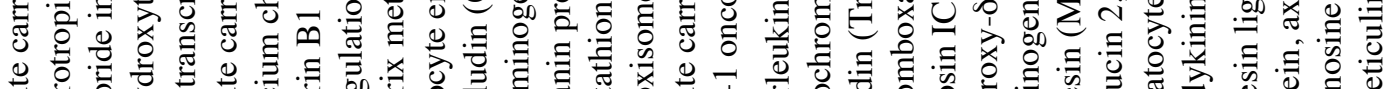

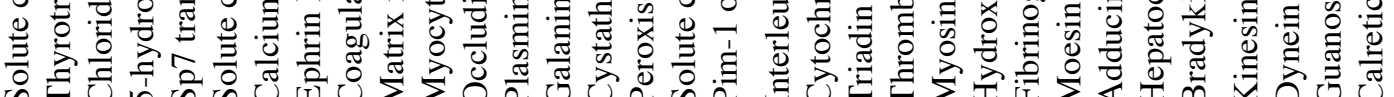

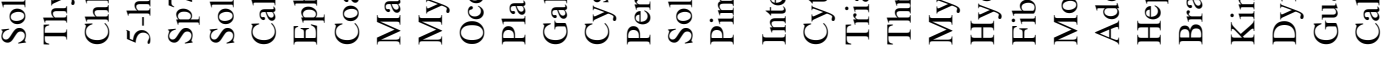

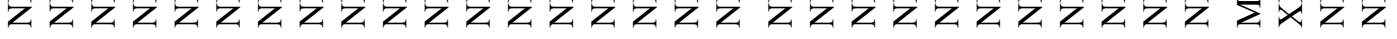




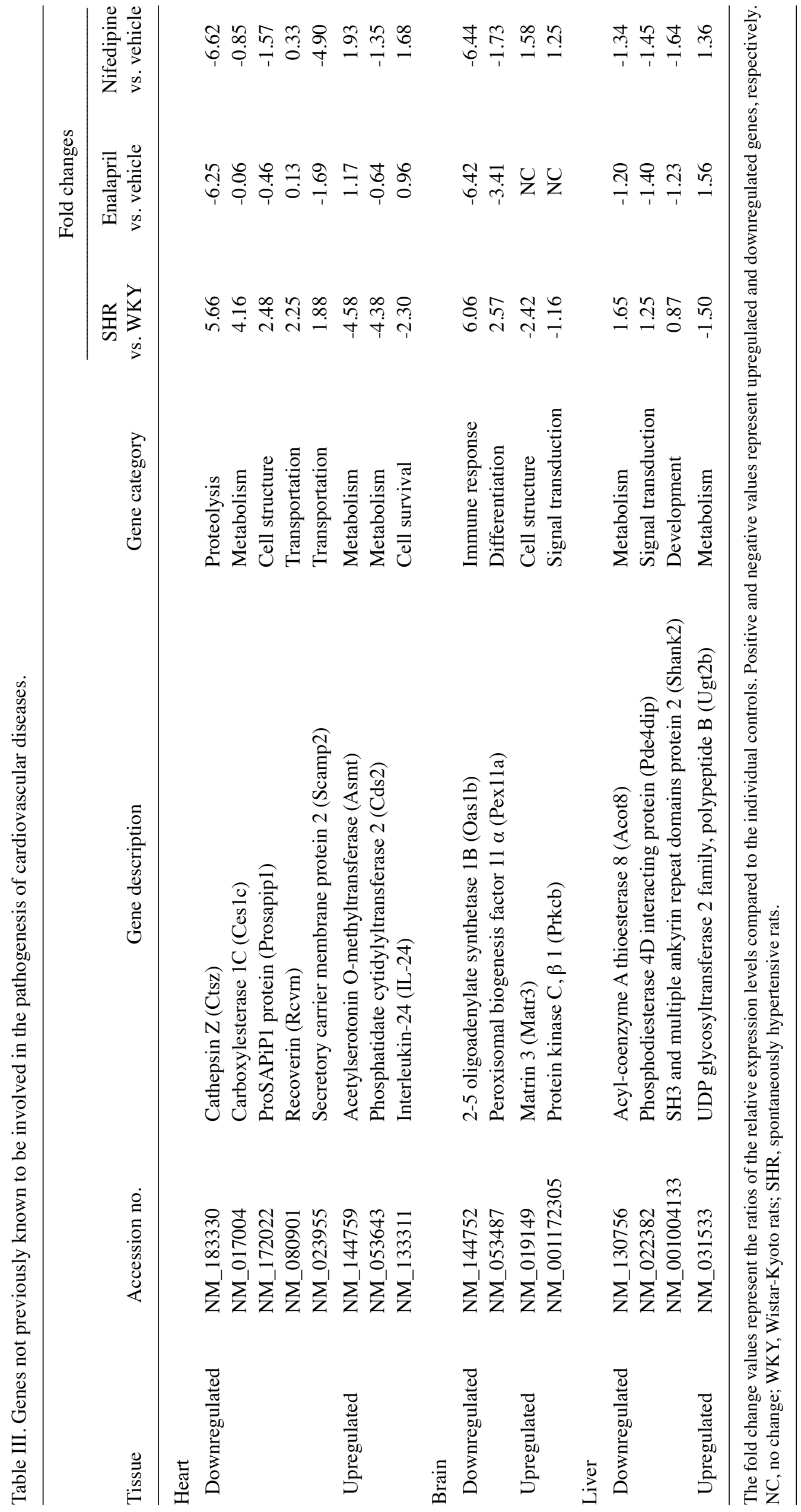




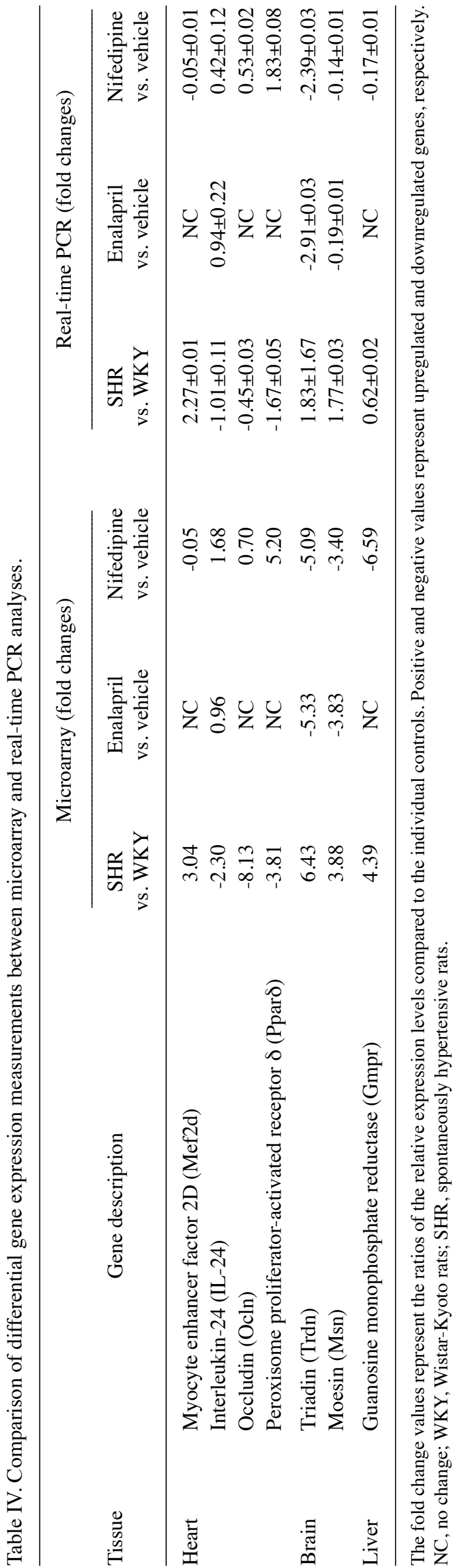

In the converse analysis, 1,887, 283 and 267 genes showed decreased expression in the heart, brain and liver, respectively, from SHR compared with the WKY controls. Among these downregulated genes, expression of 1,490, 36 and 50 genes in the heart, brain and liver, respectively, was increased in SHR treated with enalapril compared with untreated SHR. Similarly, the expression of 1,564, 102 and 47 of these genes in the heart, brain and liver, respectively, was increased by nifedipine administration.

Several of the differentially expressed genes are known to be involved in the pathogenesis of cardiovascular diseases, as shown in Table II. Expression of 23 genes was markedly elevated in these three tissues from SHR compared with the WKY controls, whereas 10 genes showed decreased expression. Among these differentially regulated genes, analysis of heart samples from SHR showed that the expression of 11 genes was increased, while the expression of 7 genes was decreased. The expression of 9 genes was increased in brain samples from SHR, while the expression of 2 genes was decreased. Analysis of liver samples showed that the expression of 3 genes was elevated, while 1 was decreased. Markedly, these gene expression patterns were reversed by administration of either enalapril or nifedipine. We also identified 16 differentially expressed genes that had not previously been reported to be involved in the pathogenesis of cardiovascular diseases (Table III). In heart samples from SHR, 5 genes were upregulated compared with the WKY controls, and 3 genes were downregulated. In brain samples from SHR, 2 genes were upregulated, while 2 genes were downregulated. In liver samples from SHR, 3 genes were upregulated, while 1 gene was downregulated. Among these three tissues, the most prominent changes in gene expression were observed in the heart. These data show that administration of SHR with antihypertensive drugs led to changes in gene expression in a drug- and tissue-specific manner.

Validation of microarray data by real-time PCR. To validate the microarray data, the expression levels of 7 genes were measured using real-time PCR (Table IV). Expression of IL-24 in heart samples from SHR was increased by enalapril compared with SHR controls, but the expression of occludin and Pparo did not change. Expression of triadin and moesin was elevated in brain samples of SHR compared with WKY controls, but it was decreased after administration of enalapril. Gmpr and Mef2d showed no change in expression in the heart or liver from SHR compared with WKY controls. In addition, the elevated expression of triadin, moesin, Gmpr and Mef2d in the heart, brain, and liver of SHR was lowered by nifedipine, while decreased expression of IL-24, occludin and Pparo in the heart of SHR was raised by nifedipine. These results correlate with those from our microarray data.

Effect of IL-24 on the expression of genes associated with cardiovascular disease in MOVAS cells treated with $\mathrm{H}_{2} \mathrm{O}_{2}$. The overproduction of intracellular ROS, such as superoxide anions $\left(\mathrm{O}_{2}{ }^{-}\right)$, hydrogen peroxide $\left(\mathrm{H}_{2} \mathrm{O}_{2}\right)$, and hydroxyl radicals $\left(\mathrm{OH}^{-}\right)$, has been implicated in the pathogenesis of cardiovascular diseases, including hypertension, heart failure, atherosclerosis and diabetes (12). ROS can induce the expression of genes associated with cardiovascular diseases 

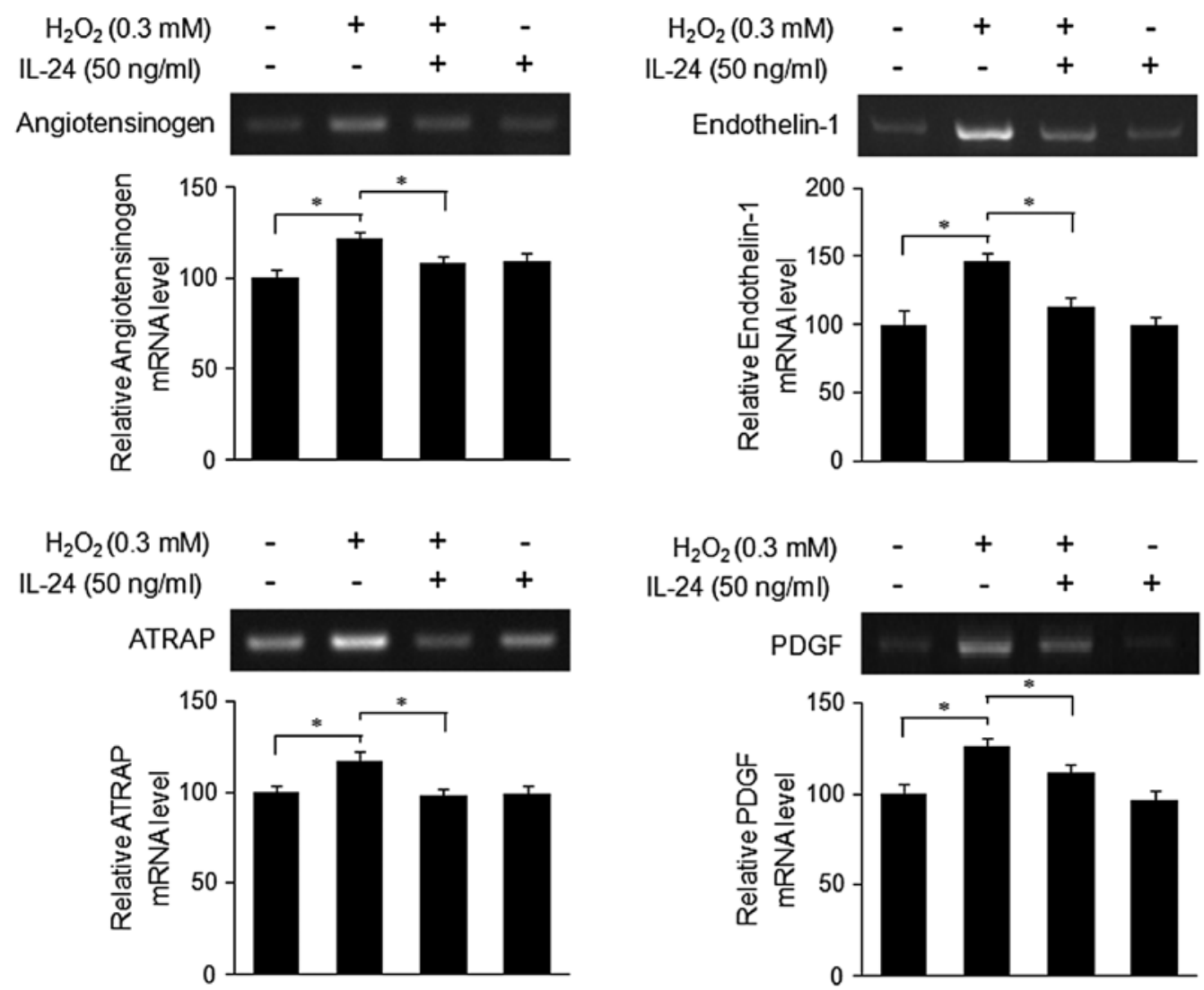

Figure 2. Effect of IL-24 on the expression of genes associated with cardiovascular disease in MOVAS cells treated with $\mathrm{H}_{2} \mathrm{O}_{2}$. Following serum starvation for $12 \mathrm{~h}$, MOVAS cells were treated with $0.3 \mathrm{mM} \mathrm{H}_{2} \mathrm{O}_{2}$ for $6 \mathrm{~h}$ in the presence or absence of rhIL-24 (50 ng/ml). (Upper panels) Total cytoplasmic RNA was isolated from the cells, and RT-PCR was performed for 28 cycles using the indicated PCR primers, as described in the Materials and methods. Data are representative of three independent experiments. (Lower panels) The bar graphs were generated by quantifying the relative band intensities, which were normalized with $\beta$-actin mRNA expression levels. The data represent the means \pm SEM of data from three independent experiments, which yielded similar results. ${ }^{*} \mathrm{P}<0.05$ compared with the individual controls.

in vascular smooth muscle cells (VSMCs) $(13,14)$. IL-24 is among the differentially expressed genes described above, but no role of IL-24 in cardiovascular disease has been reported. To investigate the effect of IL-24 on ROS-mediated gene expression, RT-PCR was performed in MOVAS cells treated with $\mathrm{H}_{2} \mathrm{O}_{2}$ in the presence or absence of rhIL-24. The expression of angiotensinogen, endothelin-1, ATRAP and PDGF was increased by treatment with $\mathrm{H}_{2} \mathrm{O}_{2}$, but reduced by rhIL-24 (Fig. 2). There was no effect of IL-24 alone on the expression of the above genes. These data suggest that IL-24 might play a role in the suppression of ROS-induced gene expression in cardiovascular disease.

\section{Discussion}

Hypertension is a key risk factor for cardiovascular mortality through target-tissue damage induced on the heart, brain, liver, kidney and vessels by its various effects $(15,17)$. It has been reported that the heart and brain tissues are damaged by high blood pressure, leading to heart hypertrophy and stroke (16). In addition, the liver is the main tissue of angiotensinogen synthesis, and angiotensin II causes liver fibrosis, which results in portal hypertension (17). Previous studies found that administration of SHR with antihypertensive drugs caused changes in gene expression in the kidney and bladder tissues $(18,19)$.
However, there are few similar studies using the heart, brain or liver tissue from SHR treated with the antihypertensive drugs enalapril or nifedipine.

The objective of our study was to determine how these drugs affect gene expression in SHR tissues other than kidney or bladder. In the heart, brain, and liver tissues from SHR, we found that oral administration of these drugs altered the expression of 33 genes involved in cardiovascular disease pathogenesis. In these tissues, we also identified 16 differentially expressed genes that were not previously known to be involved in cardiovascular disease pathogenesis (Table III). We confirmed the differential gene expression found using microarray analysis (Table II) by real-time PCR on selected genes, including Mef2d, IL-24, occludin, Ppard, triadin, moesin and Gmpr (Table IV). The biological roles of these genes in cardiovascular disease have been demonstrated, but no studies have shown changes in their expression in an animal model of hypertension as a result of administration with enalapril and nifedipine. Our identification of genes known to be associated with cardiovascular disease validates this experimental system.

Our microarray analysis also identified 16 genes that have not been implicated in cardiovascular disease or shown to be regulated by antihypertensive drugs (Table III). Among these is cathepsin, a lysosomal cysteine protease that is associated 
with the pathogenesis of cancer, bone remodeling, and cardiovascular disease through degradation of extracellular matrix (ECM) proteins $(20,21)$. ECM degradation activity of cathepsin contributes to the pathogenesis of various diseases, including cancer and cardiovascular disease $(20,22)$. Cathepsin Z, listed in Table III, is the only carboxypeptidase in the cathepsin family (23) that is highly expressed in gastric cancer and hepatocellular carcinoma and contributes to tumor development $(24,25)$. Secretory carrier membrane protein (SCAMP), a family of highly conserved tetraspanning transmembrane proteins, has been known to play a role as a carrier to the cell surface in post-golgi recycling pathways (26) and to be involved in endocytosis $(27)$ and exocytosis $(28,29)$. SCAMP2 has been characterized as a novel serotonin transporter (SERT)interacting protein that regulates the subcellular distribution of SERT (30). It is known that mice overexpressing SERT generate pulmonary arterial hypertension $(31,32)$. In this context, the genes listed in Table III including cathepsin $\mathrm{Z}$ and SCAMP2 may be novel therapeutic targets in cardiovascular disease. However, this needs to be further defined for correlation with cardiovascular disease.

Among the differentially expressed genes found in this study is IL-24, which was previously known as melanoma differentiation antigen 7 (mda-7) exhibiting proapoptotic activity in a variety of tumor cells and belonging to the IL-10 family of cytokines (which also includes IL-19, IL-20, IL-22 and IL-26) (33). Recent studies have reported several anticancer functions of IL-24, including cancer-specific induction of apoptosis, cell cycle regulation, and the ability to inhibit angiogenesis (34). IL-24 has also been known to selectively inhibit the growth and migration of mouse VSMCs (MOVAS cells), but the precise mechanisms involved remain unclear (35). A series of the molecular pathogenesis are common in cancer and vascular diseases, such as atherosclerosis and hypertension (36), but little is known about the role of IL-24 on the pathogenesis of cardiovascular diseases. In this study, we are the first to show that IL-24 might be capable of inhibiting expression of cardiovascular disease-associated genes in ROS-treated mouse VSMCs (MOVAS cells). ROS play important roles in the pathophysiology of cardiovascular diseases, such as hyperlipidemia, diabetes mellitus, hypertension, ischemic heart disease, and chronic heart failure. In addition, $\mathrm{H}_{2} \mathrm{O}_{2}$ itself promotes rat VSMC proliferation (37), and exogenous $\mathrm{H}_{2} \mathrm{O}_{2}$ can induce production of endogenous $\mathrm{H}_{2} \mathrm{O}_{2}$ by activating cellular NAD(P)H oxidase (38). We found that IL-24 regulates the expression of inflammation- and hypertension-related genes, such as angiotensinogen, endothelin-1, ATRAP and PDGF, in $\mathrm{H}_{2} \mathrm{O}_{2}$-treated MOVAS cells. These data suggest that IL-24 may be a novel therapeutic target for hypertension as well as cardiovascular disease.

In conclusion, our study is the first report on the gene expression profiles from the heart, brain and liver of SHR orally treated with enalapril or nifedipine. These data may aid in the delineation of the molecular mechanisms that underlie the potential efficacy of enalapril and nifedipine against cardiovascular disease. In addition, the differentially expressed genes identified here may be potential biomarkers as well as novel targets for the prevention of cardiovascular disease, potentially providing valuable information for the development of antihypertensive drugs.

\section{Acknowledgements}

This study was supported by the Korea Science and Engineering Foundation through the Research Center for Women's Diseases (R11-2005-017-02002) and the Bio-industry Technology Development Program (111066-3), Ministry for Food, Agriculture, Forestry and Fisheries, Republic of Korea.

\section{References}

1. Trippodo NC and Frohlic ED: Similarities of genetic (spontaneous) hypertension. Man and rat. Circ Res 48: 309-319, 1981.

2. Okamoto K and Aoki K: Development of a strain of spontaneously hypertensive rats. Jpn Circ J 27: 282-293, 1963.

3. Klingbeil AU, Schneider M, Martus P, et al: A meta-analysis of the effects of treatment on left ventricular mass in essential hypertension. Am J Med 115: 41-46, 2003.

4. Ménard J, Campbell DJ, Azizi M and Gonzales MF: Synergistic effects of ACE inhibition and Ang II antagonism on blood pressure, cardiac weight, and renin in spontaneously hypertensive rats. Circulation 96: 3072-3078, 1997.

5. Hosomi N, Mizushige K and Ohyama H: Angiotensin-converting enzyme inhibition with enalapril slows progressive intima-media thickening of the common carotid artery in patients with noninsulin-dependent diabetes mellitus. Stroke 32: 1539-1545, 2001.

6. Croom KF and Wellington K: A Review of the use of modifiedrelease formulations in the treatment of hypertension and angina pectoris. Drugs 66: 497-528, 2006.

7. Ueng KC, Lin MC, Chan KC and Lin CS: Nifedipine gastrointestinal therapeutic system: an overview of its antiatherosclerotic effects. Expert Opin Drug Metab Toxicol 3: 769-780, 2007.

8. Tostes JM: Effects of hypertension on abdominal wall healing: experimental study in rats. Surg Today 37: 215-219, 2007.

9. Yono M, Yamamoto Y, Yoshida M, Ueda S, et al: Effects of doxazosin on blood flow and mRNA expression of nitric oxide synthase in the spontaneously hypertensive rat genitourinary tract. Life Sciences 81: 218-222, 2007.

10. Spijkers LJ, Janssen BJ, Nelissen J, et al: Antihypertensive treatment differentially affects vascular sphingolipid biology in spontaneously hypertensive rats. PLoS One 6: e29222, 2011.

11. Sul D, Kim H, Oh E, Phark S, et al: Gene expression profiling in lung tissues from rats exposed to formaldehyde. Arch Toxicol 81: 589-597, 2007.

12. Touyz RM and Schiffrin EL: Reactive oxygen species in vascular biology: implications in hypertension. Histochem Cell Biol 122: 339-352, 2004.

13. Ruef J, Hu ZY, Yin LY, Wu Y, et al: Induction of vascular endothelial growth factor in balloon-injured baboon arteries. Circ Res 81: 24-33, 1997.

14. Chua CC, Hamdy RC and Chua BH: Upregulation of vascular endothelial growth factor by $\mathrm{H}_{2} \mathrm{O}_{2}$ in rat heart endothelial cells. Free Radic Biol Med 25: 891-897, 1998.

15. Cohuet $\mathrm{G}$ and Struijker-Boudier H: Mechanisms of target organ damage caused by hypertension: therapeutic potential. Pharmacol Ther 111: 81-98, 2006.

16. Mancia G, De Backer G, Dominiczak A, Cifkova R, et al: 2007 guidelines for the management of arterial hypertension: the Task Force for the Management of Arterial Hypertension of the European Society of Hypertension (ESH) and of the European Society of Cardiology (ESC). Eur Heart J 28: 1462-1536, 2007.

17. Lugo-Baruqui A, Muñoz-Valle JF, Arévalo-Gallegos S, et al: Role of angiotensin II in liver fibrosis-induced portal hypertension and therapeutic implications. Hepatol Res 40: 95-104, 2010.

18. Okuda T, Sumiya T, Mizutani K, et al: Analyses of differential gene expression in genetic hypertensive rats by microarray. Hypertens Res 25: 249-255, 2002.

19. Yono M, Yoshida M, Yamamoto Y, et al: Identification of potential therapeutic targets in hypertension-associated bladder dysfunction. BJU Int 105: 877-883, 2009.

20. Liu J, Sukhova GK, Sun JS, Xu WH, et al: Lysosomal cysteine proteases in atherosclerosis. Arterioscler Thromb Vasc Biol 24: 1359-1366, 2004.

21. Sevenich L, Schurigt U, Sachse K, Gajda M, et al: Synergistic antitumor effects of combined cathepsin B and cathepsin Z deficiencies on breast cancer progression and metastasis in mice. Proc Natl Acad Sci USA 107: 2497-2502, 2010. 
22. Chapman HA, Riese RJ and Shi GP: Emerging roles for cysteine proteases in human biology. Annu Rev Physiol 59: 63-88, 1997.

23. Nägler DK, Storer AC, Portaro FC, Carmona E, et al: Major increase in endopeptidase activity of human cathepsin B upon removal of occluding loop contacts. Biochemistry 36: 12608-12615, 1997.

24. Krueger S, Kalinski T, Hundertmark T, Wex T, et al: Upregulation of cathepsin $\mathrm{X}$ in Helicobacter pylori gastritis and gastric cancer. J Pathol 207: 32-42, 2005.

25. Wang J, Chen L, Li Y and Guan XY: Overexpression of cathepsin $\mathrm{Z}$ contributes to tumor metastasis by inducing epithelial-mesenchymal transition in hepatocellular carcinoma. PLoS One 6: e24967, 2001.

26. Castle A and Castle D: Ubiquitously expressed secretory carrier membrane proteins (SCAMPs) 1-4 mark different pathways and exhibit limited constitutive trafficking to and from the cell surface. J Cell Sci 118: 3769-3780, 2005.

27. Fernández-Chacón R and Südhof TC: Novel SCAMPs lacking NPF repeats: ubiquitous and synaptic vesicle-specific forms implicate SCAMPs in multiple membrane-trafficking functions. J Neurosci 20: 7941-7950, 2000.

28. Fernández-Chacón R, Achiriloaie M, Janz R, et al: SCAMP1 function in endocytosis. J Biol Chem 275: 12752-12756, 2000.

29. Guo Z, Liu L, Cafiso D and Castle D: Perturbation of a very late step of regulated exocytosis by a secretory carrier membrane protein (SCAMP2)-derived peptide. J Biol Chem 277: 35357-35363, 2002.

30. Liao H, Ellena J,Liu L, Szabo G, et al: Secretory carrier membrane protein SCAMP2 and phosphatidylinositol 4,5-bisphosphate interactions in the regulation of dense core vesicle exocytosis. Biochemistry 46: 10909-10920, 2007.
31. Müller HK, Wiborg O and Haase J: Subcellular redistribution of the serotonin transporter by secretory carrier membrane protein 2. J Biol Chem 281: 28901-28909, 2006.

32. MacLean MR, Deuchar GA, Hicks MN, et al: Overexpression of the 5-hydroxytryptamine transporter gene: effect on pulmonary hemodynamics and hypoxia-induced pulmonary hypertension. Circulation 109: 2150-2155, 2004.

33. Sainz-Perez A, Gary-Gouy H, Gaudin F, et al: IL-24 induces apoptosis of chronic lymphocytic leukemia B cells engaged into the cell cycle through dephosphorylation of STAT3 and stabilization of p53 expression. J Immunol 181: 6051-6060, 2008.

34. Lebedeva IV, Emdad L, Su ZZ, Gupta P, et al: mda-7/IL-24, novel anticancer cytokine: Focus on bystander antitumor, radiosensitization and antiangiogenic properties and overview of the phase I clinical experience (Review). Int J Oncol 31: 985-1007, 2007.

35. Chen J, Chada S, Mhashilkar A and Miano JM: Tumor suppressor MDA-7/IL-24 selectively inhibits vascular smooth muscle cell growth and migration. Mol Ther 8: 220-229, 2003.

36. Ross JS, Stagliano NE, Donovan MJ, Breitbart RE, et al: Atherosclerosis: a cancer of the blood vessels? Am J Clin Pathol 116 (Suppl): S97-S107, 2001.

37. Rao GN and Berk BC: Active oxygen species stimulate vascular smooth muscle cell growth and proto-oncogene expression. Circ Res 70: 593-599, 1992.

38. Li WG, Miller FJ Jr, Zhang HJ, Spitz DR, et al: Active oxygen species stimulate vascular smooth muscle cell growth and protooncogene expression. J Biol Chem 276: 29251-29256, 2001. 